\title{
Reflexión sobre una intervención histórica en la ciudad de Santiago: El caso del cerro Santa Lucía
}

\author{
Patricio H. Duarte G.
}

\section{Filiación}

Arquitecto U. Chile. Profesor Asistente Depto. de Historia y Teoría de la Arquitectura. Cátedra de Historia de la Arquitectura Chilena y Americana. Estudiante en el Programa Doctoral Universidad Politécnica de Madrid-Universidad de Chile.

\section{Resumen}

Reflexión sobre la visión crítica del proyecto arquitectónico desde la óptica de su repercusión en el ámbito urbano-arquitectónico; se medita acerca de la dimensión transformadora en que incurre la mayor parte de las veces, la intervención arquitectónica en la ciudad, y de la responsabilidad del arquitecto en la construcción de una continuidad histórico-urbana y su compromiso con el pasado. La preexistencia en cuanto condicionante -u omisión mejor dicho- del proyecto arquitectónico, ha marcado -negativamente- nuestra tradición urbano-arquitectónica ${ }^{1}$.

\section{Palabras claves}

Cerro Santa Lucía, tradición urbana arquitectónica, continuidad histórica.

\begin{abstract}
This article reflects upon projects in architecture from a critical point of view and the urban and architectural repercussions of such projects as well. Also the way in which such architecture projects transform the city is reflected upon, and how the architect should take on the responsibility of building a historical and urban continuity and also be committed to a common past. All that precedes an architecture project conditions that project, but often it is omitted, this has marked our urban and architectural tradition negatively.
\end{abstract}

\section{Key words}

Santa Lucia hill, urban and architectural tradition, historical continuity.

\section{Introducción}

1. Aspectos teóricos

2. El caso del cerro Santa Lucía

2.1.- Primer acto: la situación original, el cerro Huelén Prehispánico

2.2.- Segundo acto: el cerro Santa Lucía Colonial

2.3.- Tercer acto: el cerro Santa Lucía Decimonónico

Conclusión

Referencias

\footnotetext{
${ }^{1}$ El presente escrito es un extracto de trabajo realizado para el curso: "Arquitectura y Cultura de la Conservación. Teoría y Práctica de la Intervención en lugares históricos", dictado por el Arqto. Francisco de Gracia, como parte del Programa Doctoral Universidad Politécnica de Madrid - Universidad de Chile, 2002.
} 


\section{Introducción}

Creemos que, históricamente, la ciudad de Santiago ha evolucionado en términos urbano-arquitectónicos mediante un proceso de "desconstrucción" que da cuenta de una voluntad de transformación permanente que ha beneficiado la discontinuidad histórica.

Nuestro desarrollo histórico, está marcado por quiebres, muchas veces, abruptos, y por el espejismo de un progreso la mayor parte de las veces imitativo y mal entendido. Así, se ha establecido una mentalidad que privilegia y legitimiza la innovación como objetivo socio-cultural, descartando y desprestigiando la herencia del pasado que rápidamente es considerada obsoleta y cuestionable. Ello habla, quizás, de las carencias de una cultura relativamente nueva, sin el peso de una tradición profunda 0 , mejor dicho, que no se asume en propiedad o no se ha sabido reconocer.

Desempeña un rol determinante en la situación descrita -en el ámbito arquitectónico- la condición sísmica local, lo cual impone una transformación del medio construido, sobre todo en el pasado, cuando las técnicas y sistemas constructivos eran más limitados. Un sentimiento de transitoriedad y de estoicismo ante la adversidad que supone la pérdida material, marca el carácter nacional, además de -como lo señala el historiador, Alfredo Jocelyn-Holt- condicionar nuestra noción histórica de orden.

... Comenzamos diciendo que la imagen que nos retrata es la de un potencial sísmico amenazante que está en la conciencia fantasmal de cada uno de nosotros. Esto ya nos dice bastante acerca del tipo de orden que apreciamos y el que creemos que nos individualiza. Por cierto, un orden sólido, pero ni tanto. Una solidez soberbia si no fuera que va acompañada de la duda. Lo nuestro es un orden que no nos exime de la intranquilidad. Nos sentimos a resguardo, aunque estamos todo el tiempo un tanto "espirituados" porque en lo más profundo sospechamos que en cualquier momento se alteran los ejes que nos soportan y refuerzan. En los recesos de nuestra conciencia, la sensación de orden que tenemos es la de una gran construcción incólume que, a pesar de todas las prevenciones, en un mero instante y sin aviso previo se puede venir abajo. Nuestro orden, lejos de ser seguro, valga la paradoja, es precario. Y me atrevería a sostener que es tanto más precario cuanto más se afirma su solidez.

(Jocelyn-Holt, 1998).

Creemos que esta apreciación inicial provee una mirada amplia para intentar comprender el modo cómo se establece el vínculo entre proyecto y ciudad, y donde, algunas veces -como pareciera ser el caso chileno- existe una mentalidad que condiciona fuertemente la manera cómo la sociedad se relaciona con el pasado y, consecuentemente, la relevancia que ésta le asigna a la ciudad como discurso histórico continuo.

La excesiva extensión que presenta la ciudad de Santiago, fruto de un proceso de expansión permanente que se inicia desde fines del siglo XIX, es resultado, entre otras causas, de la búsqueda de nuevas localizaciones por parte de determinados grupos sociales -estratos medios y alto de la sociedad-con una actitud que desestima la ciudad existente y prefiere conformar otra nueva. 


\section{1.- Aspectos teóricos}

"Al desprenderse la América de la monarquía española, se ha encontrado semejante al Imperio romano, cuando aquella enorme masa cayó dispersa en medio del Antiguo Mundo. Cada desmembración formó entonces una nación independiente, conforme a su situación o a sus intereses; pero con la diferencia de que aquellos miembros volvían a restablecer sus primeras asociaciones. Nosotros ni conservábamos vestigios de lo que fue en otro tiempo; no somos europeos, no somos indios, sino una especie media entre los aborígenes y los españoles. Americanos por nacimiento y europeos por derecho, nos hallamos en el conflicto de disputar a los naturales los títulos de posesión y de mantenernos en el país que nos vio nacer, contra la oposición de los invasores; así nuestro caso es el más extraordinario y complicado".

\section{Simón Bolívar, discurso de Angostura}

El escrito precedente es representativo del dilema que ha enfrentado la realidad americana. Proceso histórico marcado por oscilaciones y cambios de orientación, donde la sucesión de alteraciones - radicales en más de una oportunidad- ha impedido una continuidad histórica consistente dificultando, por lo mismo, la formación de una identidad y su consolidación.

Al menos reconocemos tres fases, como parte de esta dinámica histórica: prehispánica, colonial, y republicana. Estas tres etapas determinan, a su vez, dos quiebres o inflexiones históricas significativas para nuestra evolución histórica: el momento en que se inicia la conquista de América por parte de España y el momento en que se produce la independencia política de las colonias americanas respecto del poder imperial español.

En ambas oportunidades los eventos históricos propiciaron una alteración radical de las condiciones imperantes, originando procesos que rechazaron la realidad existente. Con la conquista española, se interrumpió abruptamente del desarrollo cultural precolombino; éste fue suplantado violentamente en algunos casos, por la cultura del conquistador.

Al momento de la Independencia, las elites dirigentes desconocieron también el pasado americano; ellas renegaron ideológicamente de la etapa colonial, propiciando la instauración de un modelo republicano inspirado en el liberalismo europeo dieciochesco, como manera de superar el sistema imperial impuesto en América.

En las dos ocasiones, las etapas que se gestaron anularon premeditadamente la tradición cultural que se había logrado consolidar en el curso de los años ${ }^{2}$.

Cada etapa histórica presenta, a su vez, subdivisiones menores que, igualmente, dan

\footnotetext{
${ }^{2}$ Es claro que esta circunstancia histórica fue particularmente más dramática al producirse el quiebre entre la etapa precolombina y la etapa colonial, pero del mismo modo el inicio de la etapa republicana significó, en definitiva, que se obviara la configuración barroca-mestiza de América, claro exponente de la síntesis cultural trascendente que se había logrado desarrollar en el continente.
} 
http://revistaurbanismo.uchile.cl

cuenta de discontinuidades y cambios de dirección. En el período republicano, y particularmente en el caso chileno, hay dos sub-etapas: la primera adquiere una connotación oligárquica, si bien está imbuida del espíritu liberal independentista, y la segunda -a partir de la tercera década del siglo XX- en que, finalmente, se instaura con propiedad dicha concepción política.

Restaría mencionar que, en el campo específico de la historia de la arquitectura, existen autores que se han hecho cargo de esta realidad histórica dando forma a un lúcido pensamiento teórico-historiográfico sobre el quehacer arquitectónico local. Es el caso de la arquitecta argentina, Marina Waisman, quien ha realzado la condición discontinua del proceso arquitectónico americano; igualmente destaca el deslumbramiento siempre presente de la sociedad local ante una evasiva modernidad. Al respecto, señala Waisman (1990):

"... Pero hay además otra circunstancia que hace difícil la continuidad histórica en nuestras ciudades. Pues dicha continuidad precisa del respeto a la ciudad y a la arquitectura existentes, y es una característica bastante general de la mentalidad del latinoamericano de la parte sur del continente, característica que sólo recientemente comienza a revertirse, el desprecio por el pasado y el entusiasmo por la modernidad, por todo lo que represente - generalmente de un modo superficialel progreso".

El argentino, Roberto Fernández, establece por su parte, que esta persistente búsqueda de lo moderno es una actitud que se explica, quizás, por la condición de continente en gestación que ha supuesto históricamente el medio americano - "nuevo mundo"- y que lo ha convertido en un campo propicio para la experimentación.

"Sobre los residuos del doble fenómeno colonizador de América -el de la primera operación española de la conquista y organización de las Indias Occidentales y el de la inserción en el progreso decimonónico según el triunfo de las corrientes liberales - se inaugura, en el contexto americano, la vigencia persistente de una actitud de experimentación, de puesta en marcha de novedades e innovaciones en relación con una sociedad y un territorio entendido como laboratorio. La fuerza constitutiva de la conquista original y de los gestos civilizatorios de las élites dieciochescas marca indeleblemente la realidad americana, y sobre todo, los contrastes irresolutos entre la naturaleza y la cultura/tecnología o, en otro orden, la dualidad entre la apariencia de modernidad liberal, laicista, industrial y urbana, y la omnipresencia de un marco de tradicionalidad conservadora-populista, religiosa, preindustrial o agrarista y rural".

(Fernández, 1998).

Un enfoque similar es el que desarrolla el arquitecto chileno Enrique Browne al analizar la arquitectura contemporánea latinoamericana, al señalar que ésta... ha evolucionado dentro de una permanente tensión entre "espíritu de la época" y "espíritu del lugar". Entre su ubicación en el tiempo y su ubicación en el espacio. Sin entender esto difícilmente se puede explicar su desenvolvimiento. (Browne, 1988). El espíritu de la 
época representaría la modernidad exógena, símbolo del desarrollo universalista y que seduce con su discurso progresista, mientras que el espíritu de lugar se relaciona con los valores locales propios a una realidad cultural trascendente.

Para Cristián Fernández Cox, arquitecto chileno, este conflicto no existiría dado que, según su parecer, la influencia externa es la que ha dominado largamente en la producción arquitectónica local.

"¿Por qué parece ser que desde fines del siglo XVIII, nuestra arquitectura ha sufrido el sesgo recurrente a desplazar las categorías endocéntricas de su propia realidad, hacia las categorías ajenas de los exocentros de que dependemos? ¿Es esta enajenación una fatalidad insuperable de nuestra condición objetiva de periferia, o hay también factores subjetivos inducidos por nosotros mismos? ¿Estamos condenados a ser quejosos espectadores de hechos que competen siempre a responsabilidades ajenas, o hay un margen de factores que está en nuestras propias manos resolver? En verdad, los problemas que afronta una sociedad y sus posibilidades de resolverlos, dependen de la interacción entre dos polos: un polo subjetivo que es el modo peculiar como la sociedad aprecia y afronta esa realidad. Analógicamente, para las sociedades vale lo que para las personas: su destino depende en parte de sus circunstancias, pero también de su actitud frente a ellas".

(Fernández Cox, 1990)

Valgan las ideas generales expresadas, como ayuda para interpretar a continuación la historia y presencia actual de uno los lugares más característicos de Santiago: el cerro Santa Lucía. Si bien éste no constituye una obra de arquitectura, su condición de elemento urbanamente reconocible e históricamente significativo para nuestra ciudad, permite asimilarlo a la idea de un "edificio" inserto en la ciudad, y presumir que en él se manifiestan problemáticas que puedan comprobar el supuesto inicialmente planteado.

\section{El caso del cerro Santa Lucía}

\section{1.- Primer acto: la situación original, el cerro Huelén Prehispánico}

"Un día Caycayvilu, fuerza de las aguas, rompió las fuentes del gran abismo y las cataratas de los cielos fueron abiertas. La potente cola de Caycayvilu levantaba mareas tan enormes que toda la tierra se inundaba. Y moría toda la carne que se mueve sobre la tierra, así de aves como de ganado y bestias y de todo reptil que anda arrastrándose sobre la corteza y todo hombre. Y las aguas prevalecían sobre la tierra creciendo en gran manera; todas las montañas que había debajo de los cielos fueron cubiertas. $Y$ desde el hombre hasta la bestia y los reptiles y las aves del cielo eran raídos de la faz de la tierra. Aconteció entonces que, por la boca de los volcanes, aparecieron los Pillanes para salvar a los hombres y a las bestias. Y los Pillanes llamaron a Trentén, fuerza de la tierra y enemigo mortal de Caycayvilu. Y la tierra comenzó a levantar montes muy altos, empujada por la fuerza de Trentén; los hombres subían y subían para no morir y los que no alcanzaban a ganar las cumbres eran convertidos en peces, en anfibios, en animales marinos, en aves del espacio y en bestias de las selvas. Fue muy larga la lucha; pero, al fin, triunfó Trentén. En las cimas, junto a los bosques de pehuenes, los Pillanes cogieron a las 
http://revistaurbanismo.uchile.cl

mujeres que llegado hasta ahí y se machihembraron con ellas. Y así se multiplicaron y nació la raza mapuche que por eso significa hombres de la tierra. Y se fueron las aguas $y$ en los cielos gobernó el sol y con su fuego hizo crecer árboles y vegetaciones abundantes y hermosas. Caycayvilu derrotado formó ríos y lagos que se mantuvieron prisioneros entre los brazos de Trentrén. Entonces, el jefe de cada familia subió solitario hasta la cumbre de la montaña y selló una alianza con las fuerzas de la tierra y con los animales y con los árboles y con las montañas para proteger a toda su decendencia ..."

(Leyenda mapuche sobre el Diluvio Universal)

Independiente del protagonismo que le otorga de por sí su condición geográfica, la presencia del cerro Santa Lucía, en tanto realidad significativa, se remonta al pasado prehispánico santiaguino, cuando el valle del Mapocho era habitado por una serie de comunidades indígenas. Es entonces cuando el cerro adquiere una primera connotación como lugar reconocible y trascendente. Podríamos señalar que, si bien un lugar preexiste en función de su condición física, éste adquiere la categoría de tal en el momento que el hombre es capaz de descubrir o adjudicarle una cualidad significativa con lo cual asume una condición cultural relevante. De esa manera, el peñón rocoso que irrumpe en el plano del valle señalando una relación con el cielo, es considerado como una manifestación y representación de la divinidad, algo característico de la cosmovisión prehispánica de la parte sur del continente, en que la veneración de las altas cumbres andinas es propio de la religiosidad de aquellos pueblos. Un historiador contemporáneo resume muy bien dicho significado religioso:

"... Sabemos bastante acerca del culto a las altas cumbres entre los pueblos prehispánicos, en especial los andinos. Prevalece a lo largo de todos los Andes y, lo que es más extraordinario, el culto subsiste hasta nuestros días. En general, aparece continuamente asociado a deidades que controlan la fertilidad en sus diversas manifestaciones. Conforme a antiguas creencias, las montañas serían lugares previstos de una gravitación vital muy primaria vinculada a la subsistencia de la comunidad local que les rinde devoción. Concebidas como guardianes del clima, de las aguas y la irrigación de la tierra, del ganado, de los minerales que se esconden en sus entrañas, a las montañas se les dota de poderes mágicos de cotidiana significación. Su presencia inamovible las vuelve hitos recordatorios permanentes de dicho poder. También se les percibe como sitios donde residirían los espíritus de los muertos. De consiguiente, suele atribuírseles la capacidad de causar enfermedades y tormentas. No se descarta tampoco que hayan servido como promontorios idealmente ubicados para efectuar señalizaciones. En un sentido cosmogónico más amplio, las montañas, además, parecen hacer las veces de nexo entre los tres mundos: el océano mediante supuestas conexiones subterráneas, la tierra y el cielo".

(Jocelyn-Holt, 2000).

La máxima expresión de dicha práctica religiosa tiene lugar con la cultura inca, en que las cimas andinas adquieren la condición de "adoratorios". El hallazgo de la momia de un pequeño niño en el cerro El Plomo -ubicado en el cordón cordillerano frente a la ciudad de Santiago con 5.400 metros de altura- dejado vivo allí como ofrenda, testimonia el carácter sagrado del cerro. 
http://revistaurbanismo.uchile.cl

El cerro, como lugar, primero manifiesta una cualidad sobrenatural, telúrica, y, por lo mismo, no propicia a la intervención humana; es un lugar sagrado, en estado original. En este contexto religioso se da la condición de lugar primigenia que ostentó el cerro Huelén ("dolor", denominación prehispánica), actual Santa Lucía. Todo indica que el caserío indígena que existía a sus pies, liderado por el cacique Huelén-Huara, lo utilizaba como lugar sagrado, especie de santuario menor, aunque no se puede descartar que haya servido igualmente como punto de vigilancia defensiva dado su dominio visual sobre valle. En esta primera etapa histórica el cerro Santa Lucía se constituye como lugar reconocible en que prima el mensaje que evoca las fuerzas de la naturaleza que sugieren su identidad geomorfológica.

\section{2.-Segundo acto: el cerro Santa Lucía Colonial}

"Tomado mi despacho del Marqués, partí del Cuzco por el mes de enero de DXL; caminé hasta el valle de Copiapó, que es el prencipio desta tierra, pasado el gran despoblado de Atacama; y cient leguas más adelante hasta el valle que se dice de Chili, donde llegó Almagro y dio la vuelta, por la que quedó tan mal infamada esta tierra. Y a esta cabesa e porque se olvidase este apellido, nombré a la que él había descubierto e la que yo podía descubrir hasta el Estrecho de Magallanes, la Nueva Extremadura. Pasé diez leguas adelante e poblé en un valle que se llama Mapocho, doce leguas de la mar, la ciudad de Santiago del Nuevo Estremo, a los XXIIII de hebrero de DXLI, formando Cabildo y poniendo Justicia ... Estando poblado, traje a los naturales, por la guerra e conquista que les hice, de paz; y en tanto que les duraba el propósito de nos servir, porque luego procuran cometer traiciones para se rebelar, atendí a que se hiciese la iglesia y casa, e a la buena guardia de todo lo que se convenía".

Pedro de Valdivia, carta al Emperador Carlos V, 1550.

La irrupción española en el valle del Mapocho, repercutió desde un inicio en la continuidad histórica del cerro: a poco de asentarse los conquistadores procedieron a renombrar el cerro Huelén, él que pasó a ser conocido como cerro de Santa Lucía. Así, quedó rememorado el día en que la expedición de Pedro de Valdivia conoció el valle en el cual se fundaría luego la ciudad de Santiago (13 de Diciembre de 1540). Este cambio toponímico demuestra cómo, a partir de ese momento, el cerro en tanto "lugar" comenzó una nueva etapa al alterarse la relación hombre-lugar. El pueblo de indios que habitaba junto al cerro Huelén fue obligado a abandonar dicho emplazamiento para posibilitar la instalación hispánica, marcando el inicio del proceso de transculturación que impuso la gesta colonizadora.

Para el nuevo habitante el cerro adquiere otro significado, de menor trascendencia simbólica respecto de la etapa anterior, quedando su existencia un tanto relegada a causa del afán civilizador europeo que va imponiéndose en el medio local. Así surge la ciudad a modo de creación artificial, haciendo manifiesta en su racional traza en damero un nuevo orden que, respondiendo a una nueva mentalidad, se distancia del orden natural y místico del pasado. 


\section{REVISTADE \\ http://revistaurbanismo.uchile.cl}

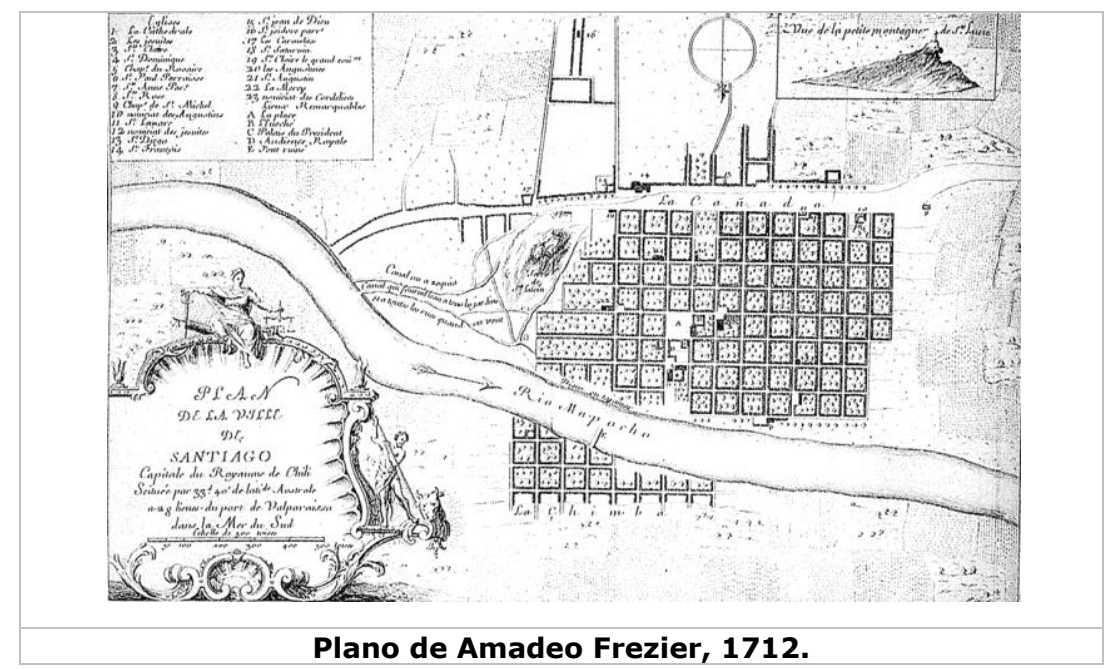

El examen de uno de los planos más antiguos que se tiene de la ciudad de Santiago (plano dibujado por Amadeo Frezier, 1712, norte abajo, cerro a la iz. arriba) permite comprender lo antes señalado. El cerro conforma uno de los cuatro bordes del trazado fundacional originado en 1541, el que, a pesar de los años transcurridos, no presenta mayores modificaciones. Hacia el norte (hacia la parte baja del plano) aparece el amplio cauce del río Mapocho. Hacia el sur se ubica La Cañada, hondonada por el cual desbordaban las aguas del Mapocho en épocas de crecidas.

Hacia el oriente, el cerro Santa Lucía y el sistema de acequias que abastecían de agua los solares en cada una de las manzanas del damero, mientras que otra hondonada menor y una extensa propiedad agrícola - la antigua chacra de García Cáceresconfinan por el poniente la forma urbana colonial. De los cuatro bordes, los tres primeros son límites geográficos que por lo mismo manifiestan su identidad en la singularidad de sus formas naturales que se contraponen con la rigidez de la traza urbanizadora.

Este aspecto evidencia una suerte de conflicto entre el orden dado por la naturaleza y el orden artificialmente impuesto por el hombre, transformador del medio, con una actitud que desconoce el paisaje y la geografía, y realza aún más el sentido artificial del damero. De cualquier forma, ello no es una particularidad sólo del caso que se está analizado, sino que es propio del urbanismo colonizador del espacio americano, con una actitud voluntarista y pragmática del conquistador.

En el caso de la ciudad de Santiago, el cerro pasa desde ser un elemento protagónico, hasta ser una suerte de accidente que se interpone ante la proyección potencial de la traza de damero, fenómeno que irá haciéndose más crítico a medida que transcurran los años y el crecimiento de la urbe comience a presionar contra los bordes que la contienen. En rigor, el cerro desde un punto de vista urbano adquirirá la condición de un umbral de desarrollo que limitará el crecimiento de la ciudad según la teoría del urbanista polaco Boleslas Malisz (Martínez, 1977). 
Ante una situación tan poco propicia para la expansión futura de la urbe, como resultó ser el emplazamiento elegido por Valdivia para asiento fundacional, cabe hallar alguna explicación razonable. Los aspectos que con el tiempo devinieron negativos, en el origen de la ciudad fueron determinantes para cumplimiento del objetivo fundacional. Así el emplazamiento acotado en sus flancos, fue, estratégicamente, un lugar fácilmente defendible frente a los naturales en la incertidumbre inicial, prevención que resultó oportuna, tal como los hechos se encargarían de demostrar a pocos meses de la fundación: el incipiente poblado fue destruido por el cacique Michimalongo el 11 de septiembre de 1541. La ciudad se redujo al polígono central de la traza fundacional algo de nueve manzanas o cuadras - el cual fue protegido con un muro de adobes a cuyo resguardo los pobladores españoles pudieron sobrevivir penosamente mientras se restablecía un ambiente de paz.

El cerro Santa Lucía, como enclave defensivo, fue desde entonces un lugar reconocible para los habitantes de la ciudad, aunque marginal por estar en el límite oriente de ella. El cerro mantuvo su apariencia agreste, de promontorio rocoso, sin mayor intervención humana salvo las baterías que se erigieron en distintas épocas en su parte alta; las más importantes fueron las que mandó construir a fines de la Colonia el último gobernador español, aunque nunca se utilizaron. Algunas construcciones que se arrimaron con el tiempo a su base, cuando la ciudad comenzó a extenderse hacia el oriente. También quedaron rastros de la explotación como cantera por los constructores de la ciudad. El cerro llevó, así, una existencia algo opaca, apareciendo como simple curiosidad respecto de la urbe. Pero, es válido pensar si la escasa figuración del Santa Lucía pudiera deberse al cordón del San Cristóbal de mayor altura, o, con mayor razón, a la imponente cordillera de Los Andes. Será en el período republicano cuando el peñón rocoso recupere nuevamente una figuración destacada al incorporarse, intervención de por medio, a la vida de la ciudad.

\section{3.- Tercer acto: el cerro Santa Lucía Decimonónico}

"¿Qué era Santiago en 1814? ¿Qué era entonces esta ciudad de tan aventajada estatura hoy para su corta edad, y que a las pretensiones más o menos fundadas de gran pueblo reúne aún las pequeñeces propias de la aldea? Santiago de 1814, para sus felices hijos un encanto, era para el recién llegado extranjero, salvo el cielo encantado de Chile y el imponente aspecto de los Andes, una apartada y triste población, cuyos bajos y mazacotudos edificios, bien alineados sobre rectas calles, carecían hasta de sabor arquitectónico. Contribuía a disminuir el precio de esta joya del titulado Reino de Chile, hasta su inmundo engaste, porque si bien se alzaba sobre la fértil planicie del Mapocho, limitaba su extensión, al norte el basural del recuesto del Santa Lucía, y el de San Miguel y San Pablo al occidente ... iQuién hubiera imaginado que aquellos inmundos ranchos que acrecían la ciudad tras del basural de la antigua Cañada, se habían de convertir en parques, en suntuosas y regias residencias, y lo que es más, que el mismo basural se había de tornar en Alameda de Las Delicias, paseo que, sin ruborizarse, puede envidiarnos para sí las más pintada ciudad de la culta Europa! Milagros todos, hijos legítimos de nuestro inmortal 12 de febrero de 1818, época en la que, rota definitivamente la valla que se alzaba entre nosotros y el resto del mundo civilizado, nos resolvimos a campear 


\section{URBANISMO \\ http://revistaurbanismo.uchile.cl}

por nuestra propia y voluntaria cuenta".

Vicente Pérez Rosales, 1882.

El siglo XIX representa en el contexto histórico chileno un período de intensas transformaciones que afectan a la sociedad chilena en su conjunto; es el momento en que, luego de superada cierta inestabilidad inicial post-independentista, los esfuerzos se concentran en dar forma al sistema republicano en propiedad. Es por lo mismo una etapa donde el progreso adquiere la condición de valor absoluto que se manifiesta en una dinámica de cambio permanente que va dando cuenta de los ideales, desafíos y nuevas realidades sociales y culturales que va generando la consolidación republicana.

Un claro testimonio de este afán modernizador lo constituye la arquitectura, la que mejor que cualquiera otra manifestación, comienza a simbolizar la condición inaugural que ese momento histórico representa para muchos. Vemos que durante el gobierno del Gral. Manuel Bulnes (1841-1851) se crea el cargo de Arquitecto de Gobierno, el cual fue ocupado, mayoritariamente hasta finalizar el siglo XIX, por profesionales franceses responsables de solucionar tanto los encargos oficiales como una creciente demanda privada; igualmente, adquirieron el compromiso de dar inicio a la enseñanza académica de la arquitectura en el medio local bajo el auspicio de la Universidad de Chile. Su accionar, sumado a otros profesionales que se incorporaron al medio local, en su mayoría europeos, se inscribió dentro de la tradición historicista europeizante, lo cual permite comprender la gama de estilos que surgen y cualifican al período; a la vez, demuestran el gusto de los grupos dominantes de la sociedad que ven en el modelo europeo la máxima aspiración del gusto y la cultura decimonónica, tal como se deja entrever en la cita precedente.

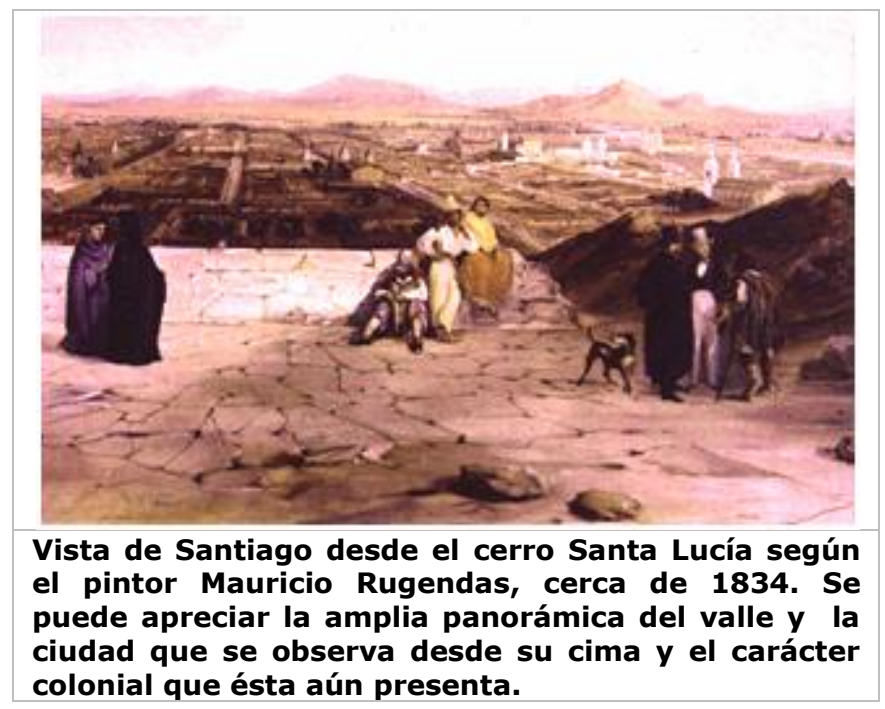

No resulta extraño que la segunda mitad del siglo XIX haya dado lugar a un intenso proceso de renovación urbano-arquitectónica para la ciudad de Santiago, dado que 
http://revistaurbanismo.uchile.cl

tanto la acción del Estado, con un importante programa de adelanto edilicio, como la significativa producción de residencias para la burguesía decimonónica, rápidamente comenzaron a cambiar el aspecto colonial que caracterizaba a la ciudad.

Ello fue alentado por el espíritu de época que veía en el Santiago colonial sólo una manifestación de atraso y falta de civilización.

Es comprensible, por lo mismo, que el cerro Santa Lucía empezara a ser considerado como signo de barbarie, respecto de una ciudad que se embellecía y progresaba. El inicio de la República no había alterado mayormente su situación; se podría estimar que incluso había acentuado su condición de lugar degradado, una espalda a principio del siglo XIX, útil como basural en su flanco norte.

Un fin más noble aunque menos conocido en la actualidad, fue que el cerro Santa Lucía acogiera en sus laderas los restos mortales de los disidentes, cuando a éstos les estaba vedada su sepultación en los cementerios oficiales, replicando lo que en tiempos pretéritos habían realizado los habitantes del valle. Una condición también marginal que aún persistía avanzado el siglo XIX, y que, cada vez más, iba convirtiendo al Santa Lucía en una suerte de problema para la ciudad.

Podría decirse que llegado este momento se había producido el enfrentamiento final entre el orden urbano-arquitectónico implantado a mediados del siglo XVI -ahora en una etapa de renovada consolidación-, y las postrimerías de lo que fuera el orden natural del valle. Pasada la primera mitad del siglo XIX, la ciudad evidencia un significativo proceso de expansión urbana tanto en dirección sur como al poniente y, en menor medida, hacia el norte y el oriente.

Los umbrales de desarrollo fueron superados, incrementándose la cantidad de terreno urbanizable. Determinante fue en esto la construcción de los tajamares - defensas ribereñas con el objeto de contener el cauce del río Mapocho-; las aguas dejaron de desbordar por la antigua cañada cuando acontecía alguna riada, ante lo cual ésta dejó de ser un accidente que se oponía al crecimiento de la ciudad hacia el sur. Igualmente, el río aminoró su condición de umbral toda vez que, una serie de nuevos puentes permitieron una mejor integración con el sector de la Chimba, en la banda norte del río.

Por su parte, la antigua Chacra de García Cáceres, fue loteada permitiendo la prolongación del damero fundacional en dirección poniente. De ese modo, las limitantes de carácter natural que constreñían la forma de la ciudad cedieron frente al ímpetu urbanizador: desaparecieron -es el caso de las cañadas - o fueron intervenidas, es el caso del río. Sólo el promontorio del cerro Santa Lucía mantiene, relativamente, intacto su carácter original. El espacio construido se va imponiendo, y el paisaje natural va perdiendo su presencia. 


\section{URBAANISMO
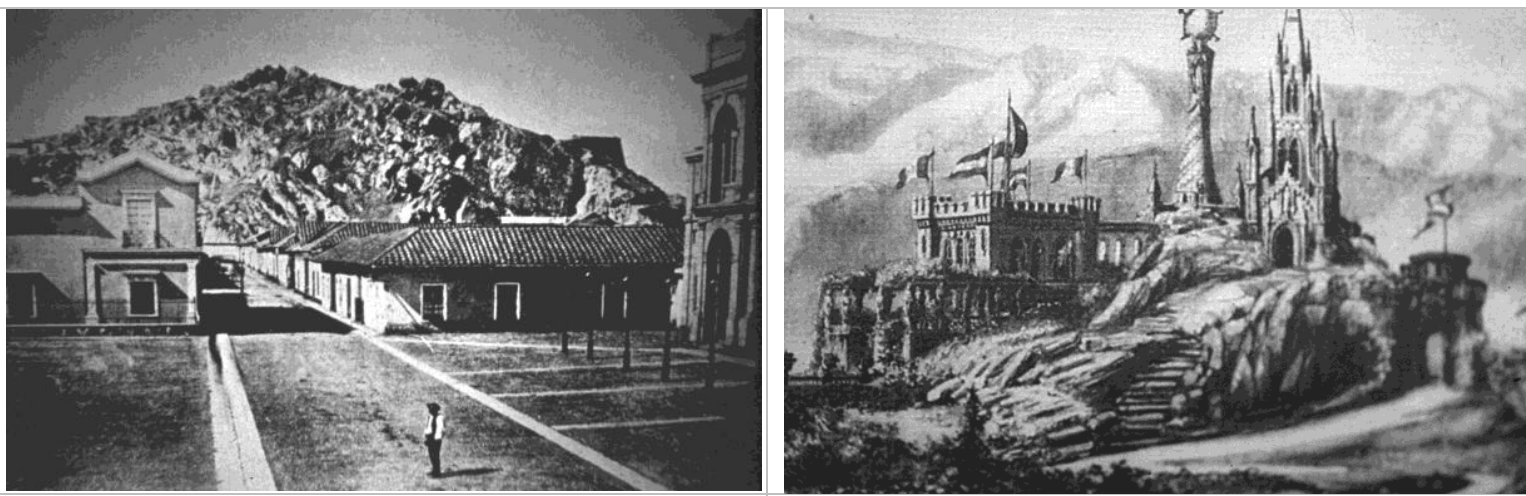

Vista del Santa Lucía desde la plazuela del Proyecto de Transformación del Santa Lucía Teatro Municipal antes de su transformación, 1872 foto c. 1860

¿De qué modo integrar entonces este reducto agreste al conjunto de la pujante urbe que se embellecía día tras día a sus pies? ¿De qué modo transformar ese montón de rocas, tal como lo catalogara Charles Darwin, en algo distinto que una simple curiosidad que desentonaba con el progreso que orgullosamente ostentaba la ciudad republicana? ¿De qué modo conciliar la modernidad con este rezago del pasado? En último término, ¿de qué modo constituirle como lugar urbano?

Estas deben de haber sido algunas de las inquietudes de más de algún personaje de la época, para quienes el aspecto del cerro debe haber representado una afrenta a la capacidad del hombre como promotor de progreso y al espíritu emprendedor propio a la mentalidad burguesa-liberal dominante en ese entonces.

El cerro Santa Lucía adquirirá la condición de lugar relevante, constituyéndose en objeto de un proyecto de intervención, no tanto para enaltecer su identidad como elemento geográfico per se, sino para desvirtuar su condición natural original. Su embellecimiento le pondría a tono con el modelo formal que ha ido adquiriendo mayoritariamente la urbe. Por lo tanto, es la ciudad la que finalmente impone su presencia al hito geográfico, transformándole en "hito urbano".

La historia atribuye a Benjamín Vicuña Mackenna, en su calidad de Intendente de la ciudad, el rol de promotor y artífice de la transformación que otorgó al cerro su nueva apariencia. Personalidad singular, valoró el cerro para darle un destino mejor al que presentaba a mediados del siglo XIX. Vicuña Mackenna es uno de los historiadores más prolíficos del período, y ese mismo interés por rescatar, valorar y difundir el pasado lo demostró en iniciativas tales como el montaje de la Exposición del Coloniaje. Sin embargo, creemos que, a pesar de ello, el proyecto de intervención delata una actitud marcada por el espíritu innovador de aquella época, expresado en la misma denominación del proyecto: una transformación.

Observamos que dicha palabra estaba en boga en aquellos años, y, particularmente, en la gestión edilicia del Intendente toda vez que, al poco tiempo de asumir su cargo presentó un plan de trabajo que guiaría su accionar municipal el cual tituló La 
http://revistaurbanismo.uchile.cl

Transformación de Santiago (20 medidas destinadas a mejorar la condición urbana de la ciudad de Santiago).

¿Hasta qué punto la transformación del cerro Santa Lucía surge como la oportunidad que mejor ejemplifica la visión sobre la ciudad que Vicuña Mackenna quería instaurar? Pienso que se puede interpretar la transformación del cerro Santa Lucía como una obra paradigmática del pensamiento de Vicuña Mackenna, estableciéndose una suerte de metáfora entre el cerro y la ciudad en su conjunto. Así, una realidad tosca e incivilizada podía dar lugar a algo bello y útil gracias al conocimiento y al esfuerzo propio, frente a las exigencias de un modo de vida civilizado. Por ello el cerro es visto como una especie de gema en bruto:

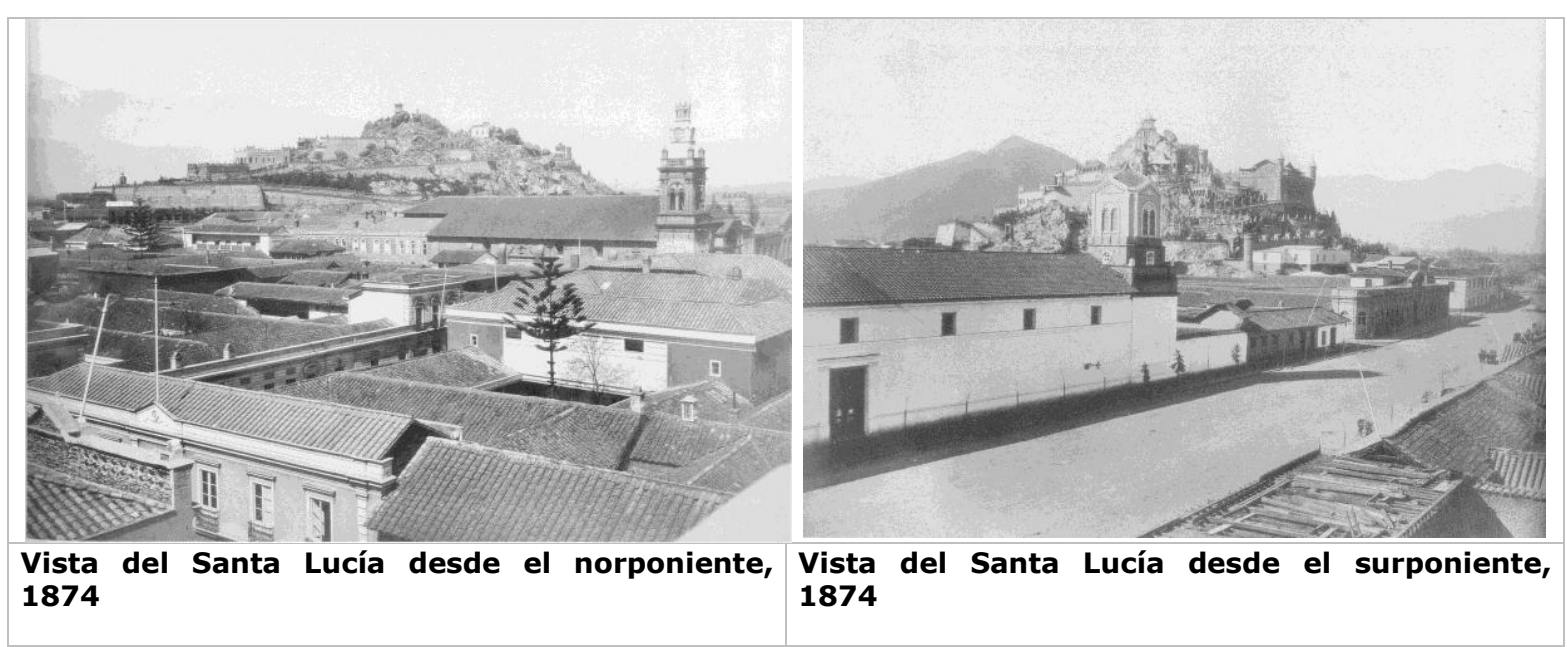

"... necesitaba únicamente un operario cualquiera que comprendiese su adaptación a los usos $i$ propósitos de las ciudades modernas, es decir, su adaptación para paseo público i sitio de reuniones populares, labrando entre las duras rocas anchas avenidas $i$ seguras carreteras, senderos pintorescos, variados jardines $i$ plantaciones, grietas i desfiladeros, edificios apropiados a sus planicies, en una palabra, lo que constituye un verdadero paseo, en el sentido moderno de esta palabra que significa recreo $i$ arte, salud e hijiene. I esto es lo que se ha hecho desde el 4 de junio de 1872 en que se instaló la primera faena de sesenta presidarios en el antiguo castillo de Hidalgo, hasta el 17 de setiembre de 1874, día en que el paseo casi terminado en todas sus partes ha sido entregado a la Municipalidad. ... Porque ya comienza a ser sabido de muchos que los jardines no son solo eras de flores sino grandes purificadores; que las pilas no son sólo vistosos surjideros de agua sino copiosos refrijerantes $i$ restauradores químicos de la atmósfera; que las estatuas no son sólo "monos" de bronce o de mármol, sino centros inevitables de mejoras autonómicas, puesto que el vecindario que se agrupa al derredor de cualquier obra de arte o de gloria, por una razón, si se quiere, por un instinto irresistible, no consiente que el basural invada las gradas de la esfijie, ni el pantano hediondo salpique los mármoles. I por esto lo preserva, mejorando el pavimento que circunda los monumentos públicos, pulimentando el 


\section{REVISTA DE \\ URB}

http://revistaurbanismo.uchile.cl

material de las aceras que a ellos conduce, embelleciendo la estructura esterior de las casas, el alumbrado, la policía, todo, en una palabra. Ejemplo vivo de esto es lo que hoi se ostenta en la capital, en cuyo vasto recinto, donde quiera que se ha erijido, en medio de la crítica de obstinadas y añejas preocupaciones, un monumento de ese jénero, el bienestar $i$ el adelanto comienzan a abrirse paso bajo sus múltiples formas".

(Vicuña Mackenna, 1874).

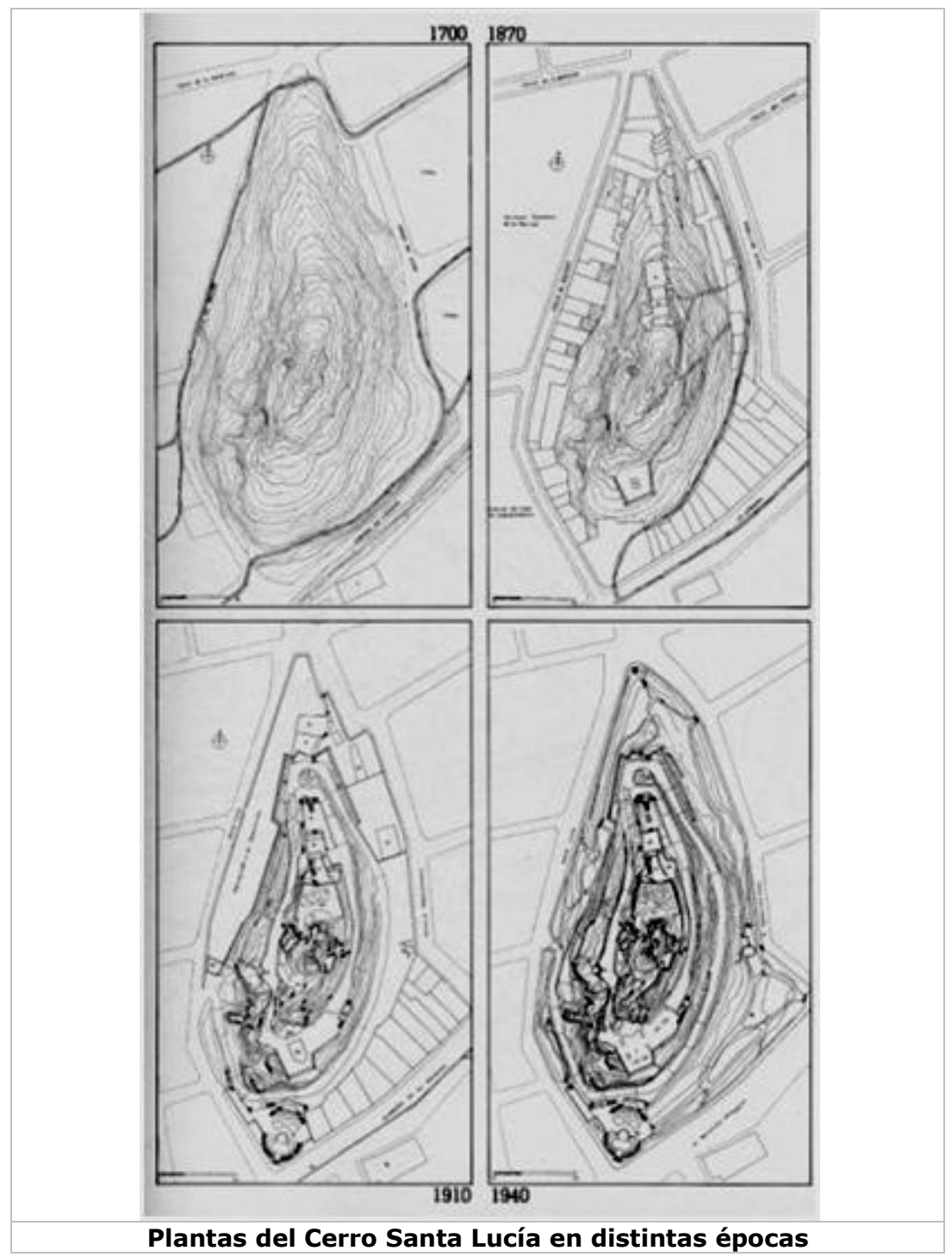

El alcance de la transformación del cerro llevada a cabo por Vicuña Mackenna permite dar forma a un último comentario. La adaptación a paseo de la ciudad del antiguo peñón significó un cambio sustancial de su apariencia, el espíritu de época se hizo sentir en la inspiración pintoresquista que dio forma a su concepción paisajista, que 
http://revistaurbanismo.uchile.cl

dio cuenta del imaginario de aquella época y de sus autores. Quizás podría asimilársele a lo que en la actualidad corresponde a un parque de entretenciones, en que se mezclaban las reminiscencias históricas con las obras de arte y las instalaciones destinadas a la simple diversión (restaurant, sala de teatro, juegos de niños, etc.).

Sin embargo, a pesar de esta innovación en el carácter y significado del cerro respecto de la ciudad, se puede constatar que éste siguió manteniendo su condición de mirador de la ciudad; es más, se puede afirmar que gracias esta intervención dicha función se vio realzada, pues facilitó el acceso a su parte alta a la población. De esta forma, el cerro recuperó su condición de elemento singular reconocible.

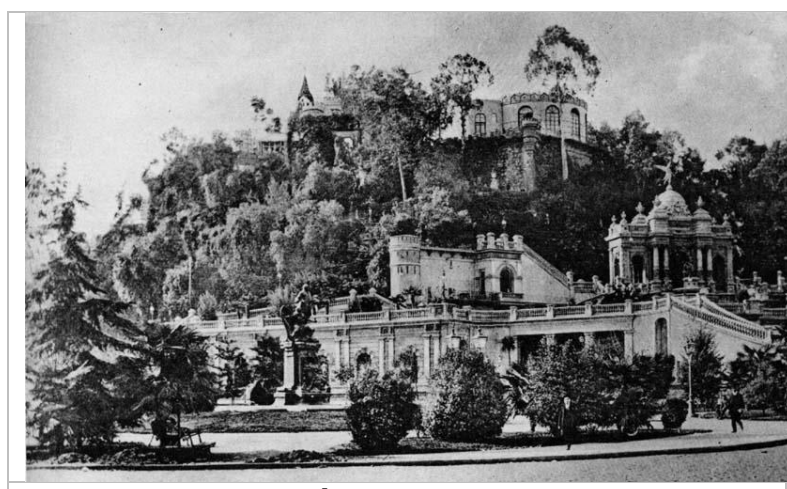

Vista del Santa Lucía desde su acceso principal

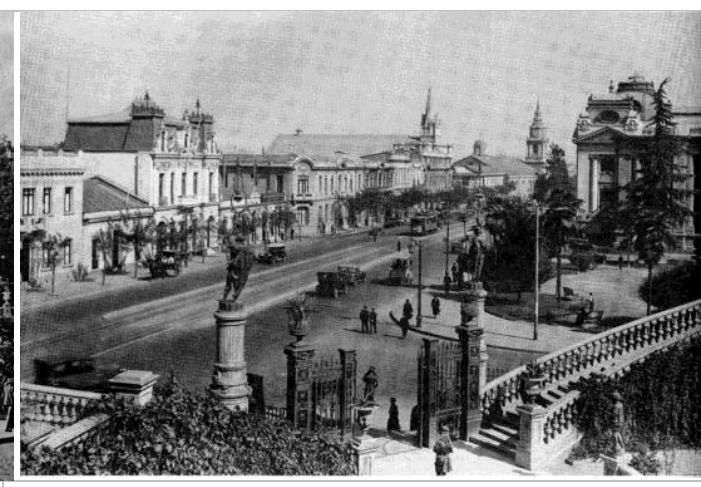

Vista de la Alameda desde la terraza de acceso al cerro Santa Lucía.

\section{Conclusión}

La urbe ha ignorado el cerro, o ha menoscabando su identidad, o bien, le ha impuesto su propio orden transformándolo y desvirtuando en alguna medida su carácter original.

No debe resultar extraño que el cerro esté enfrentando en la actualidad intervenciones de distinta índole, fruto de una dinámica urbana que se torna más intensa y amenazante para la conservación de los lugares históricos de la ciudad de Santiago.

En las últimas décadas, el cerro fue transformándose en una isla subsumida en la actividad y el crecimiento urbano en torno a él. Resulta especialmente grave a nuestro juicio, la intensidad de este fenómeno en su flanco poniente, donde un importante proceso de renovación urbano-arquitectónico se ha hecho sentir con mayor fuerza. Ello ha dado origen a una serie de edificios en gran altura que, en buena medida, están configurando una barrera que bloquea tanto la vista desde la ciudad al cerro como, igualmente, la vista de la ciudad y el valle desde siempre desde el cerro.

El cerro ya no es el elemento dominante del centro histórico de la ciudad, y también ha visto menoscabada su condición de lugar privilegiado desde donde dominar el paisaje. 
http://revistaurbanismo.uchile.cl

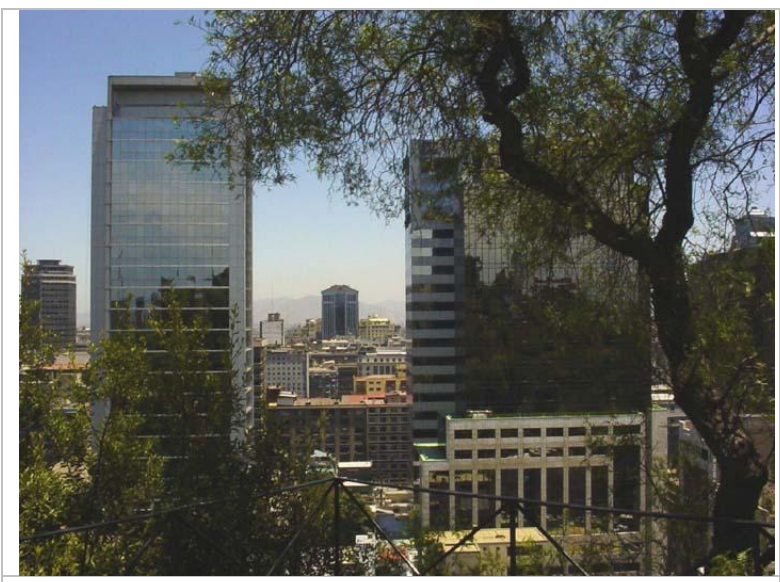

Vista hacia el poniente desde el punto más alto del Cerro Santa Lucía
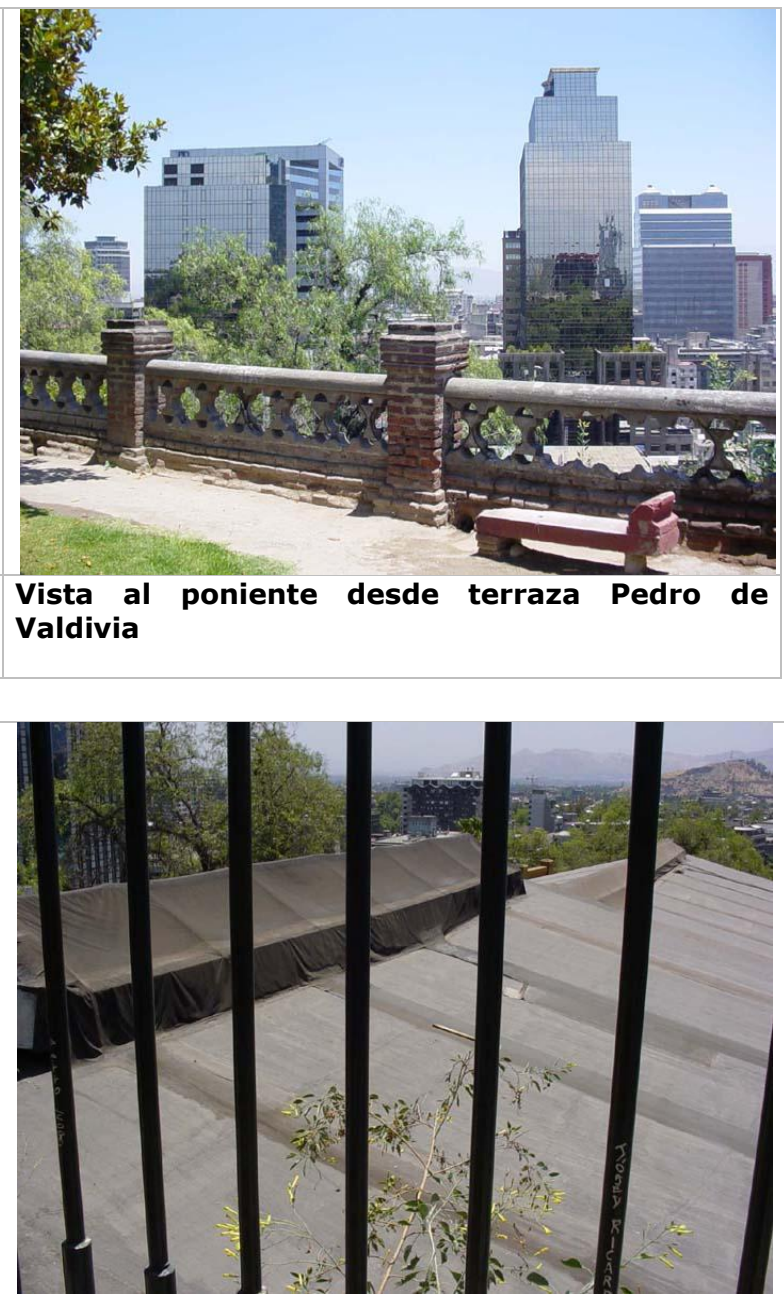

Cubierta Sala de Eventos Castillo Hidalgo desde

\begin{abstract}
terraza Pedro de Valdivia.
\end{abstract}
Castillo Hidalgo transformado en Sala de Eventos. Se aprecia estructura sobrepuesta.

El cerro aparece, principalmente desde el centro histórico, como una parcialidad, a veces incluso como una situación sub-realista o anecdótica en medio del orden urbano. Es la generosa perspectiva que posibilita la Alameda - la antigua Cañada - la vista urbana en que aún el cerro aparece en toda su presencia y carácter. Es básico por lo tanto que, buscando resguardar lo que constituye uno de los lugares más propios y característicos de la ciudad de Santiago, se resguarde su condición de mirador y objeto dominante regulando la intervención que trae consigo la dinámica urbana.

Se da pues la paradoja que los edificios de gran altura que se han construido en el centro histórico de la ciudad se ubican principalmente a menos de una cuadra, al poniente del cerro, quedando en evidencia la carencia de voluntad por preservar un bien social que debiéramos transferir al futuro en toda su dignidad. 
Por otra parte, el cerro mismo ha sido objeto de modificaciones, pérdidas e intervenciones significativas respecto de la transformación de fines del siglo XIX. Terremotos, falta de mantenimiento, descuido, desidia, falta de cultura,...variadas causas podrían explicar tales sucesos; sin embargo pareciera ser que la fortaleza de este lugar tan singular es grande; ello le ha permitido sobrepasar con relativo éxito los embates a lo largo del tiempo.

Las agresiones se pueden reconocer fácilmente; en algún momento fue la construcción del paso bajo nivel en su vértice sur-poniente, con una estética que hace alarde del automóvil como protagonista de la ciudad; hace poco la instalación de un ascensor panorámico, que facilita la expedición a los menos dispuestos a la aventura de descubrir sus senderos y subir sus desgastadas escaleras; ahora último, el castillo Hidalgo ha sucumbido a las políticas de autofinanciamiento municipal transformándose en una sala de eventos que se facilita a quien pueda pagar el importe correspondiente. ¿Qué nuevas innovaciones deparará el futuro a este histórico lugar? El sentido común desearía se comience a considerar la continuidad histórica como un valor positivo que beneficie la identidad y motive una adecuada integración en los sitios de carácter histórico.

El objetivo del urbanismo que debiera ser capaz de gestionar apropiadamente la ciudad consolidada, conforme a lo señalado por el arquitecto Francisco de Gracia, en sus conferencias recientes en Santiago.

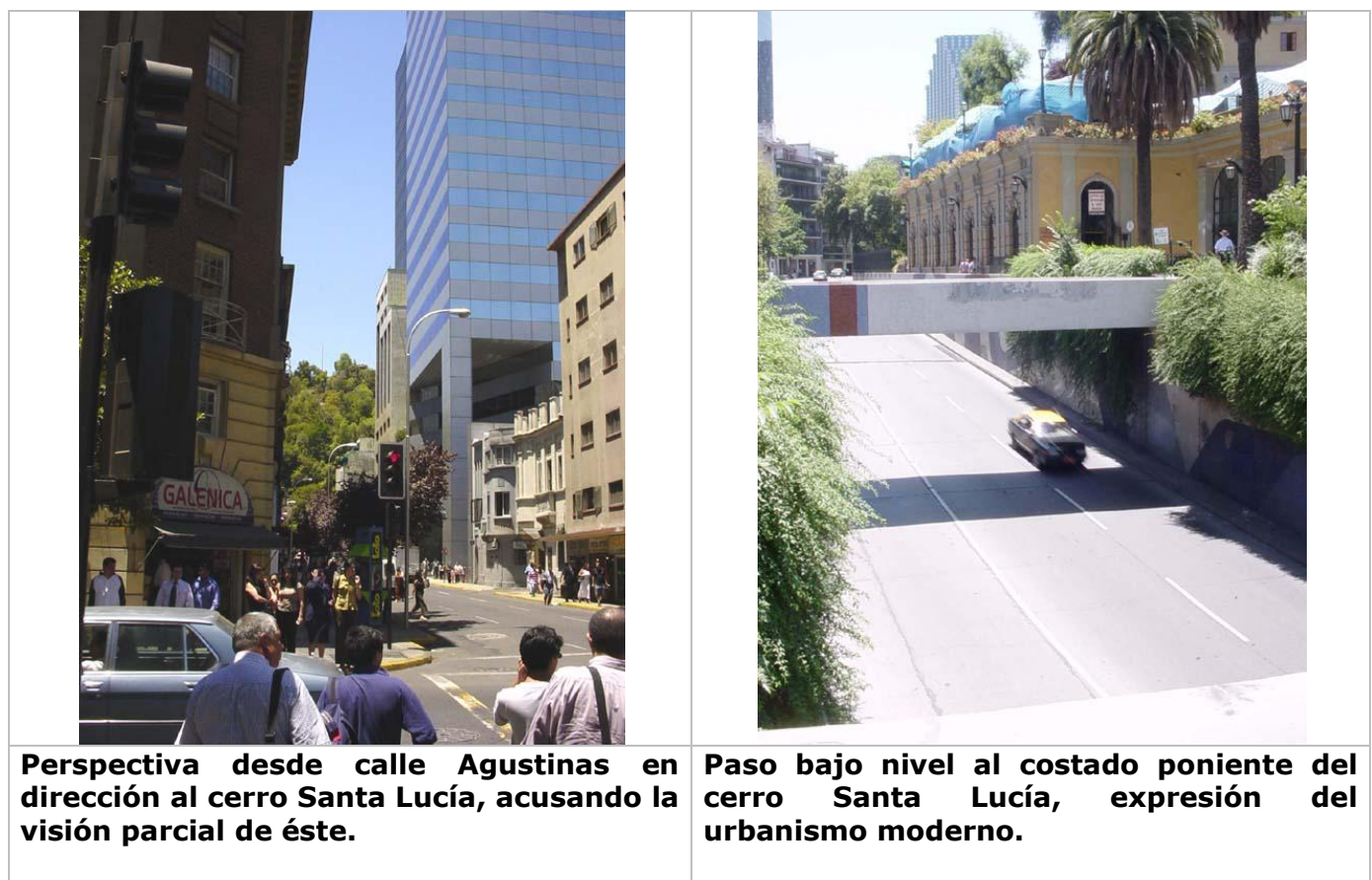




\section{Referencias}

BROWNE, E. 1988. Otra arquitectura en América Latina. Ediciones G. Gili, S.A. de C.V., México.

FERNANDEZ, C. 1990. "Hacia una modernidad apropiada: obstáculos y tareas internas" en Nueva Arquitectura en América Latina: Presente y Futuro. Ediciones G. Gili, S.A. de C.V., México.

FERNANDEZ, R. 1998. El laboratorio americano. Arquitectura, Geocultura y Regionalismo. Editorial Biblioteca Nueva, S. L., Madrid.

JOCELYN-HOLT, A. 1998. El peso de la noche. Nuestra frágil fortaleza histórica. Editorial Planeta Chilena, S. A., Santiago, 1998.

JOCELYN-HOLT, A. 2000. Historia General de Chile. 1 El Retorno de los dioses. Editorial Planeta Argentina S.A.I.C., Buenos Aires.

MARTINEZ, R. 1977. Desarrollo Urbano de Santiago 1541 - 1941. Ensayo de aplicación de la Teoría de los Umbrales a la interpretación del desarrollo histórico de la ciudad de Santiago. Documento Docente, Facultad de Arquitectura y Urbanismo, Universidad de Chile.

VICUÑA MACKENNA, B. 1874. "Álbum del Santa Lucía" en La montaña mágica. El cerro Santa Lucia y la ciudad de Santiago. Ediciones ARQ, Escuela de Arquitectura, Pontificia Universidad Católica de Chile, Santiago, 1993.

WAISMAN, M. 1993. El interior de la historia. Historiografía arquitectónica para uso de latinoamericanos. Escala, Bogotá. 